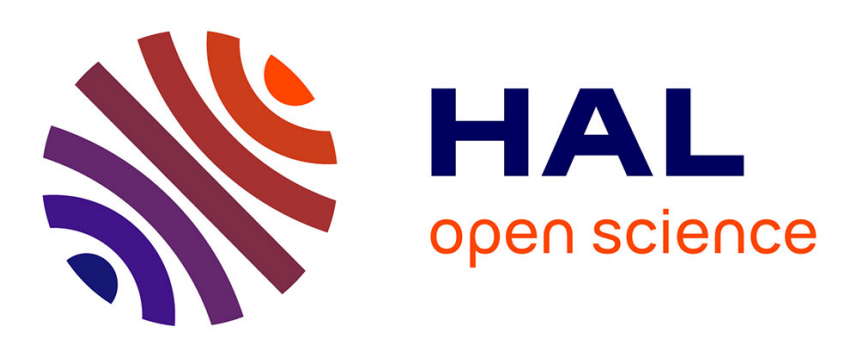

\title{
Analysis of information processing, decision making, and visual strategies in complex problem solving sport situations
}

\author{
Hubert Ripoll, Yves Kerlirzin, Jean-François Stein, Bruno Reine
}

\section{To cite this version:}

Hubert Ripoll, Yves Kerlirzin, Jean-François Stein, Bruno Reine. Analysis of information processing, decision making, and visual strategies in complex problem solving sport situations. Human Movement Science, 1995, 14 (3), pp.325-349. 10.1016/0167-9457(95)00019-O . hal-01816088

\section{HAL Id: hal-01816088 \\ https://hal-insep.archives-ouvertes.fr/hal-01816088}

Submitted on 14 Jun 2018

HAL is a multi-disciplinary open access archive for the deposit and dissemination of scientific research documents, whether they are published or not. The documents may come from teaching and research institutions in France or abroad, or from public or private research centers.
L'archive ouverte pluridisciplinaire HAL, est destinée au dépôt et à la diffusion de documents scientifiques de niveau recherche, publiés ou non, émanant des établissements d'enseignement et de recherche français ou étrangers, des laboratoires publics ou privés. 


\title{
Analysis of information processing, decision making, and visual strategies in complex problem solving sport situations
}

\author{
Hubert Ripoll ${ }^{\text {a }}$, Yves Kerlirzin ${ }^{\text {b }}$, Jean-François Stein ${ }^{\text {b }}$, Bruno Reine ${ }^{\text {b }}$ \\ ${ }^{a}$ Unité de Formation et de Recherche en Activités Physiques et Sportives, Université de Poitiers, 4 Allée \\ Jean Monnet, 86000 Poitiers, France \\ ${ }^{\mathrm{b}}$ Laboratoire de Neurosciences du Sport, INSEP, 11 Avenue du Tremblay, 75012 Paris, France \\ Article publié dans : Human movement science (ISSN 0167-9457), 1995, vol. 14, n³, pp. 325-349
}

\begin{abstract}
The aim of this research was to analyze information processing, decision making and visual search activity of boxers (French boxing) of various levels of expertise (experts, intermediates, and novices) in simulated and video problem-solving situations replicating the natural task demands. Subjects were placed in front of a screen on which a front-viewed filmed boxer, considered as an opponent, carried out different boxing manoeuvres to which they had to respond by manipulating a joystick according to previously learned responses. Two experiments were carried out. The first was used to analyse subjects' responses in situations whose level of complexity varied. Different actions carried out by an opponent (attacks, openings, and feints) were presented in each situation. In simple situations, subjects had to react to one type of manoeuvres only, whereas in complex situations they had to react to a wider variety and choose the appropriate responses. Response accuracy and reaction time were analysed. Results indicated that differences between groups occurred only in complex situations. The responses of expert boxers were more accurate but reaction time was the same in all groups. This experiment was also used to select the appropriate sequences retained for the second experiment, in which the visual behaviour of boxers was analysed by using an Eye Movement Recorder (Nac Eye Mark recorder V) during the test. The spatial (nature, number, frequency of visual fixations, and scan-paths), and the temporal (mean duration of fixation, and total duration of fixation) characteristics of the visual search activity were analysed. Results demonstrated a significant correlation between level of expertise and subjects' visual strategy.
\end{abstract}

\section{Introduction}

Sport situations requiring information processing are characterized by a high level of uncertainty forcing the player to use complex cognitive skills to give the most appropriate responses under stressful conditions. Such cognitive skills underlying decision are most frequently studied, mainly for methodological reasons, in simulated settings presented by films or slides (e.g., Malho, 1969; Bard and Fleury, 1976; Salmela and Fiorito, 1979; Ripoll, 1979,1988,1991; Allard et al., 1980; Allard and Starkes, 1980; Westphal, 1982; Ritzdorf, 1983; Godinho, 1986; Abernethy and Russell, 1987; Goulet et al., 1989; Abernethy, 1990; Helsen and Pauwels, 1990; Lerda, 1993). This consists, for instance, in analyzing the ability to recognize an opponent's action or in solving a problem situation. Results generally show that experts are more accurate and rapid in solving the problem than non-experts (see Ripoll, 1991, for an overview). But, even when such differences between populations have been demonstrated, the cognitive processes underlying production of the response, and the effect of expertise on these operations has seldom been addressed. For example, we know little about the progress of development of these operations from being a beginner to becoming an expert. Furthermore, we do not know from what level of complexity the processing capacity of novices reaches its limit and at what point the factor of expertise becames significant. This last question will be examined in the first part of our research.

One complementary way to identify these operations is to analyse the subject's visual search activity. This procedure has been used in badminton (Abernethy and Russell, 1987), soccer (Helsen and Pauwels, 1990), tennis (Goulet et al., 1989), and volleyball (Ripoll, 1988). The spatial and temporal characteristics of visual behaviour are used to identify the operations associated with the elaboration of 
responses. Experts were not only better at identifying the situation or solving the problem but they also revealed important differences in their visual search strategy which, in turn, involves the use of specific principles of organization. The visual patterns of the experts were shown to be more economical than those of non-experts, the frequency of their visual fixations being lower, and mean fixations being of a longer duration. This difference is considered to be a consequence of the general organization of the visual behaviour that is "synthetic" in experts and "analytic" in novices. A synthetic analysis consists in grouping different pieces of information rather than analysing each of them separately. This behaviour, which is used to identify the relation between spatially distant information present in the image, is made possible by directing the gaze to a position from which a maximum number of events can be observed and grouped from only one visual fixation. Resultant behaviour has been described in sport situations (e.g., Bard and Fleury, 1976; Petrakis, 1986,1987; Ripoll, 1988; Kerlirzin, 1990), and also in various everyday activities, such as observing a complex figure (Mackworth and Bruner, 1970; LevySchoen, 1972), scanning an X-ray (Papin et al., 1984), driving a car (Hella, 1983), and piloting an aircraft (Papin, 1987).

However interesting these results may be, the recording technique fails to provide precise information about the nature of the visual cues used in solving the problem. This is mainly the case in sporting situations in which, generally, a large number of items are widely distributed in the visual field and where the response has to be given under a time constraint. Thus, it is clear that efficient behaviour depends on quick analysis, minimum eye movement and chunking the different items present in the visual field rather than in focusing on several specific cues. This behaviour, used by experts, and termed an inter-event strategy by Ripoll (1991), consists in using a holistic visual pattern taking into account the relation between the different items of the figure.

The studies of visual behaviour were questioned by Abernethy and Russell (1987), and Goulet et al. (1989). These authors compared the ability of players, of different levels of expertise, to identify different filmed tennis and badminton service situations while their visual search activity was being recorded. Subjects had to predict, as soon as possible, the probable finishing position of the ball/shuttle. Results demonstrated no substantial difference related to players' expertise in visual search activity (allocation of fixations to display regions, search order, search rate, and search organization) whereas appreciable differences in response accuracy were present. The authors concluded that the limiting factor in perceptual performance was not visual access to pertinent information but the ability to extract, and to use, the information available at key fixation locations. They also questioned the interest and the validity of the analysis of visual strategies and Abernethy and Russell (1987) claimed that visual search activity was neither a fundamental cause nor a reliable indicator of differences in performance between experts and novices.

The discrepancy between these results and conclusions in classical literature on visual strategies (see Tenenbaum and Bar-Eli, 1993, for a review) is particularly striking and justifies further study of the subject. Particularly, as we think it possible that these results may have been determined by the nature of the experimental setting used by these authors. In the first place, they used filmed situations in which the information was manipulated either by occluding a spatial part of the information or by cutting the film at different moments before the ball strikes. In this last condition especially, the duration of the test presentation was probably too short (between about $500 \mathrm{~ms}$ and $1 \mathrm{~s}$ ) for a complete visual scanning process involving several saccades to be carried out. Secondly, it is possible that when complete serves were observed, the chronology of the successive elements of the service movement, appearing always in the same order, forced the player to use an identical visual pattern independent of the player's expertise. Finally, it seems possible to us that expert-related differences would only appear in long duration presentations and when the different sub-sequences of the movement do not appear in the same, and consequently, predictable order. The aim of the following research was to examine this question by analysing the behaviour of subjects at different levels of expertise in simulated martial sport problem situations such as French boxing.

Two distinct experiments were carried out. The first was a problem-solving task in which the relation between the level of complexity of the task, subjects' level of expertise and level of performance on the test were studied. Our main hypothesis was that expertise-related differences would not appear in simple situations, where a decision was unnecessary, but only in complex 
situations in which a decision was required. To reach this goal, we varied the task complexity and examined the effect of this variation on the quality (accuracy and reaction time) of the response. This experiment also consisted in a pilot study to select the appropriate sequences used in the second experiment in which the subject's visual behaviour was recorded during the test. Our aim was to identify, in a problem-solving situation, the visual behaviour related to the level of expertise of boxers. Our main hypothesis was that when the presentation was continuous, complex and long enough, visual behaviour is correlated to subjects' level of expertise.

For these reasons, we chose oculography and continuous information presentation, similar to that taking place in a natural context, over spatial occlusion technique. The latter seems best-suited for showing which information the subject uses in predicting an action and for inferring the nature of selective information pick-up, but is not adapted for describing the dynamic aspect of the visual search and the strategy employed.

\section{Experiment 1: Mental chronometry in information processing}

\subsection{Method}

\section{Subjects}

Three groups of boxers (French boxing) volunteered to take part in this experiment. There were six experts (EXP), from the French National team, aged from 22 to 33 years (mean 27.3), six intermediates (INT), training once a week and competing at the first class level, aged from 20 to 25 years (mean 23.8), and six novices (NOV) aged from 22 to 33 years (mean 26.3) with more than one year of practice but no experience in competition.

\section{Design and procedure}

Subjects had to solve different boxing problem-solving situations (French boxing), in which a boxer, considered as an opponent, was video-recorded and the image projected onto a front-viewed large screen (it is important to specify that in French boxing, strokes can be carried out with legs as well as arms). Opponent size and projection angle were similar to those encountered in natural situations. The video showed different classes of item (attacks, openings and feints) to which subjects had to respond by manipulating a joystick in such a way that responses closely correlated to the behaviour actually carried out in match situations. In each situation, five different types of item were presented: right and left attacks, openings, and right and left feints. Attacks originated from one side (left or right) and subjects had to move the joystick in the same direction with the intention of stopping the attack. Openings consisted in setting the guard low and exposing the head, or setting the guard high and exposing the chest. Subjects had to move the joystick in the direction of the opening. No response was required for feints in any of the tests. In summary, three responses were possible: two for attacks (joystick moved to the right for left attacks and to the left for right attacks), one for openings (joystick moved forward) and none for feints. Two levels of response complexity were compared. In simple situations, subjects were given instructions to react only to one class of item and to ignore the other. They had to react to attacks in Situation 1 and to openings in Situation 2. In complex situations, subjects were asked to react to both attacks and openings and to ignore feints. In conclusion, the perceptual tasks demand was similar in the three conditions making it possible to study the role of response complexity independent of other factors.

Subjects learned the S-R associations in a training session during which they were provided with knowledge of results. During the testing period, no KR was given and subjects were encouraged to respond as correctly as possible without exceeding the time limit Continuous presentation forced the subjects to either respond quickly or ignore the event in order to prepare themselves for subsequent items which appeared at a rate of 22 items/minute with an inter-item duration of $2 \mathrm{~s} \pm 700 \mathrm{~ms}$. Between the different actions, the demonstrator produced normal preparatory movements of French boxing (bounces and arm movements). These movements could not be mistaken for the principal actions to which the subjects had to respond. 
In spite of efforts to simulate the natural setting of boxing, clear differences were still apparent. They had to do, on the one hand, with the two-dimensional nature of the information presented, and on the other with responses that did not allow normal coupling of perception and action. As a result, the conclusions of this research will, necessarily, be restricted to studied simulated situations. Inferences to real practice settings will remain limited.

\section{Scenarios and video recording}

Scenarios were written by a coach so as to simulate the perceptual demands of the "real-world" activity of French boxing as accurately as possible. Scenarios of 60 second duration were composed of the same events (number and nature), but the order of appearance was different. Twenty two items (ten attacks, seven openings, and five feints) were displayed on each video and six sequences (two conditions were laid down for each film) were used. Sequences were recorded by a camera $(3 / 4 \mathrm{U}$ Matic Betacam) set at $4 \mathrm{~m}$ from an expert demonstrator standing in a ring. Each sequence featured a different scenario learned by the demonstrator prior to being recorded. During the recording, acoustic signals were given to the demonstrator to indicate to him when he had to carry out each event of which the order had been learned.

\section{Response recording and data collection}

Sequences were projected by a SONY VPH $600 \mathrm{QJ} / \mathrm{Q} / \mathrm{M}$ trichrome overhead projector onto a $200 \mathrm{X}$ $170 \mathrm{~cm}$ screen placed $3 \mathrm{~m}$ in front of the subject. Video tapes were frame-coded (frame code SONY FCG700) so that, during the test, each movement of the joystick was recorded, on-line, by a computer (PC Compacq 2662 A) interfaced with the video tape. Consequently, it was possible to identify the nature of each response and the time elapsed between the triggering of the stroke by the demonstrator, which consisted in the stimulus onset, and the response of the subject. RTs were always higher than $400 \mathrm{~ms}$ and no erroneous responses were made between events. This shows that subjects reacted to a proper stimulus and not to a preparatory movement. Each subject carried out six tests (two in each situation) of which the order of passing was counter-balanced. Between tests, subjects rested for 5 minutes. For each subject and in each test the mean reaction time and the mean percentage for each type of response were calculated.

\section{Dependent variables}

Dependent variables were the percentage of responses, and the reaction times to produce them. We considered: (1) reactions to attacks, to which subjects had to respond by producing defensive responses. We distinguished between reactions to attacks independent of errors of decision, that is to say irrespective of the Bide of the responses, and correct decisions in which appropriate S-R associations (right-sided responses to right-sided attacks and left-sided responses to left-sided attacks) were given; (2) reactions to openings, to which subjects had to respond by producing an attack; (3) feints that had to be ignored.

\section{Statistical analysis}

A one-way ANOVA, with level of expertise as the between-subjects factor, was used to analyse the effect of expertise on each dependent variable in situations 1, 2 and 3. A two-way ANOVA was carried out on RTs, with groups (3) as the between-subjects factor and situations (3) as the repeated measure.

\subsection{Results and discussion}

\section{Situation 1: Responses to attacks in simple situations}

Responses refer to the identification of attacks while ignoring openings and feints. Results showed no effect of groups for the percentage of correct responses (EXP $=93.3 \%$ vs. INT $=86.6 \%$ vs. NOV $=$ $\left.88.3 \% ; \mathrm{x}^{2}(2, N=18)=2.17, p>0.05\right)$ and for RTs $(\mathrm{EXP}=546 \pm 103.2 \mathrm{~ms}$ vs. INT $=574 \pm 88.2 \mathrm{~ms}$ 
vs. $\mathrm{NOV}=534 \pm 56.8 \mathrm{~ms} ; \mathrm{F}(2,15)>0.05)$. No incorrect decisions were made. This result confirmed that the effect of expertise does not appear in simple situations.

False alarms. False alarms consisted in responding to feints instead of ignoring them. Because feints consisted in attacks that were initiated and then quickly stopped after a brief movement of the limb, it was normal that boxers, in cases of false alarms, considered them to be attacks and responded by warding off. Results showed that the number of false alarms was high and not different in each group $(\mathrm{EXP}=36.6 \%$ vs. INT $=36.6 \%$ vs. $\mathrm{NOV}=33.3 \%)$. This shows that all subjects favoured security by responding to feints. For RT, no effect of level of expertise was found ( $\mathrm{EXP}=510 \pm 150.6 \mathrm{~ms}$ vs. INT $=574 \pm 88.2 \mathrm{~ms}$ vs. $\mathrm{NOV}=534 \pm 56.8 \mathrm{~ms} ; \mathrm{F}(2,15)>0.05)$.

\section{Situation 2: Responses to openings in simple situations}

Responses refer to the identification of openings while ignoring attacks and feints. Results showed no group effect for the percentage of responses (EXP $=45.2 \%$ vs. INT $=40.4 \%$ vs. NOV $=38 \% ; x^{2}(2$, $N 18)=1.08, p>0.05)$ and for RT $(\mathrm{EXP}=564 \pm 209.7 \mathrm{~ms}$ vs. INT $=530 \pm 200 \mathrm{~ms}$ vs. $\mathrm{NOV}=515 \pm$ $109.9 \mathrm{~ms} ; \mathrm{F}(2,15)>0.05)$. No incorrect decisions, consisting in responses to attacks or feints, were made. This confirms that the effect of expertise does not appear in simple situations. The lack of a significant difference in RTs between attacks and openings is surprising. Indeed, two responses were possible for attacks while only one response was possible for openings. In the latter case, because no selection was required, RTs should have been reduced. A possible explanation is that signals delivered by openings are ambiguous and take more time to be identified than signals delivered by attacks. This is clearly supported by results from percentage of response for attacks $(89.4 \%$, mean values for the three groups) as compared with percentage of response for openings (41.2\%). We will see later that this effect is amplified in more complex situations.

\section{Situation 3}

Subjects had to respond to attacks and openings while feints had to be ignored.

Responses to attacks in complex situations. Responses were reactions to attacks independent of decisional errors. Results showed that experts were significantly more efficient in responding to attacks $(78.3 \%)$ than intermediates $(51.6 \%)$ or novices $(68.3 \%)$ with a significant difference $\left(\mathrm{x}^{2}(1, N=18)=\right.$ $15.33, p<0.005)$. Complementary analyses showed that EXP were significantly different from INT $\left(\mathrm{x}^{2}\right.$ $=14.68, p<0.0001)$, and from NOV $\left(\mathrm{x}^{2}=2.54, p<0.05\right)$, and that INT were significantly different from NOV $\left(\mathrm{x}^{2}=5.33, p<0.02\right)$. This confirms that the effect of expertise appears when the level of complexity of the task is high. However, we cannot explain why novices were better than intermediates and this partially weakens our conclusion. However, it should be recalled that our "novices" were not inexperienced having had more than one year of practice; they differed from the intermediates in not having had experience in competition.

Moreover, analysis of reaction time showed no significant effects of groups (EXP $=544 \pm 29.2 \mathrm{~ms}$ vs. INT $=549 \pm 98 \mathrm{~ms}$ vs. $\mathrm{NOV}=523 \pm 23.8 ; \mathrm{F}(2,15)>0.05)$. The lack of any significant differences in RT in the situation in which three types of response were possible (joystick moved to the left, to the right or forward) while only two were possible in Situation 1 (joystick moved to the left or to the right) and one in Situation 3 (joystick moved forward) is questionable. A possible explanation is that all these situations involved a speed-accuracy trade-off. When complexity increased (from S.1 to S.3), subjects fixated their response time and thereby decreased the accuracy of their response. This probably results from the continuous presentation forcing subjects to respond before the subsequent event occurred. Under such conditions, the lack of any difference in RT suggests that expertise results more from the ability to detect pertinent cues (of which the number is related to the level of expertise) than as a higher speed of response.

Correct responses for attack in complex situations. Correct decisions corresponded to correct S-R associations with respect to the response side. Results showed that responses were significantly better in $\operatorname{EXP}(68.3 \%)$ than in INT $(43.3 \%)$ and $53.3 \%$ in $\operatorname{NOV}\left(x^{2}(1, N=18)=12.78, p<0.0017\right)$. EXP 
were different from INT $\left(\mathrm{x}^{2}=12.65, p<0.0004\right)$, and from NOV $\left(\mathrm{x}^{2}=4.71, p<0.03\right)$, but there was no significant difference between INT and NOV $\left(\mathrm{x}^{2}=2, p>0.05\right)$. RT was not related to the level of expertise ( $\mathrm{EXP}=533 \pm 90 \mathrm{~ms}$ vs. INT $=542 \pm 99 \mathrm{~ms}$ vs. NOV $=496 \pm 48 \mathrm{~ms})$. The decrease in correct decisions (relating to Situation 2) was quite similar in each group (EXP $=10 \%$ vs. INT $=8.3 \%$ vs. $\mathrm{NOV}=15 \%$ ). It may appear surprising that RTs associated with correct decision (in which the processing of the stimulus could have been completed before the response was triggered) were somewhat faster (but not statistically different) than those resulting from a combination of correct and erroneous decisions in which the processing of the stimulus was completed before the response was triggered (EXP $=544 \mathrm{~ms}$ vs. $533 \mathrm{~ms}$, INT $549 \mathrm{~ms}$ vs. $542 \mathrm{~ms}$, NOV 523 vs. $496 \mathrm{~ms}$ ). This probably results, on the one hand, from the fact that subjects were operating under temporal pressure and that they may not have had the time to complete processing prior to responding. On the other hand, it is important to note that the two categories of correct and incorrect defense decisions were made a posteriori, after the experiments had been performed.

Responses for openings in complex situations. Only one kind of response was possible when the opponent made openings. Results showed that subjects, whatever their level of expertise, generally ignored openings (EXP $7.1 \%$ vs. INT $11.6 \%$ vs. NOV 9.5\%). Several remarks made by boxers and coaches concerning this result provide one possible explanation. They pointed out that openings were more ambiguous to detect than attacks because they could be confused with a feint that boxers chose to ignore. Furthermore, it was less detrimental to ignore an opening than not to detect an attack. Finally, a lower number of openings, compared to attacks (we have already noted that this ratio was chosen to be as close as possible to actual conditions) may produce a probability bias effect affecting responses. Whatever the hypotheses, it seems that the more complex the problem solving situation, the more the subjects concentrated on attacks and ignored openings. This confirms previous results from Kerlirzin (1990) showing that when only openings were presented, the percentage of correct detections reached $99 \%$ for experts, $87 \%$ for intermediates and $86 \%$ for novices. In our situation in which subjects had to respond to a wide variety of items, openings were neglected and their detection rate drastically decreased (to about $10 \%$ ).

False alarms. Results showed many false alarms in each group. The higher the level of expertise the higher the percentage of false alarms. It reached $46.6 \%$ in EXP (for all subjects) vs. $30 \%$ in INT (5 subjects over 6 responding) and 23\% in NOV (for all subjects). Another explanation might help to clarify the low level of responses to openings and the high level of false alarms. It pertains to the ratio between potential attacks $(n=15 / 22=68.13 \%)$ including attacks $(n=10)$ and feints $(n=5)$, related to openings $(n=7 / 22=31.87 \%)$ heightened probability for an item to be an attack has probably induced subjects to adopt a more conservative expectation, leading to over estimation of potential attacks and to under estimation of openings. In any event, this attentional bias does not contradict the fact that in our situation experts seemed more conservative than intermediates.

Inter-situation effects. Inter-situation comparisons showed the effect of complexity on the different types of responses and on strategies used by subjects (see Fig. 1 and Table 1).

Comparison of situations 1 and 2 showed that reaction to attacks was easier for the three groups (mean percentage $=89 \%$ ) than reaction to openings $(41 \%)$. Responses to events were easier in simple tasks, when subjects had to pay attention to only one class of item (Situation 1 and 2), than in complex tasks (Situation 3). This effect of complexity was less appreciable when subjects had to respond to attacks $(89 \%$ vs. $66 \%)$ than to openings $(41 \%$ vs. $9.5 \%)$. Our result can be attributed not only to an easier discrimination of attacks, as compared to openings, but also to the strategy used by subjects who seemed to prefer to ignore an opening rather than reject an attack. Subjects seemed to favour safety against risk. The level of false alarms was high, whatever the level of complexity, when they had to react to attacks ( $35.5 \%$ vs. $33.3 \%$ ), and negligible when subjects had to react to openings (about 10\%). This confirms the ambiguous status of false alarms and the reason why they tend to be identified more as an attack than as an opening. It is surprising to note that the reaction times associated with complete processing (in complex situations) did not differ from the reaction times associated with incomplete processing (in simple situations): $\mathrm{F}(2,15)=0.57, p>0.05$. Our main hypothesis is that the rate of sequence presentation, as a deadline, forced subjects to give their response prior to the following sequence. The principal consequence is that the effect of complexity acts only upon the number of 
correct detections without modifying response speed.

In conclusion, our results show that the simulation of sport problem solving situations may indeed reveal behaviours involved in actual field situations. They confirm previous experiments using problem solving procedures in sport (e.g. Malho, 1969; Bard and Fleury, 1976; Salmela and Fiorito, 1979; Ripoll, 1979,1988; Allard et al., 1980; Allard and Starkes, 1980; Ritzdorf, 1983; Westphal, 1982; Abernethy and Russell, 1987; Goulet et al., 1989; Abernethy, 1990). We have demonstrated that the effect of expertise appears only in complex situations. This might mean that expertise lies, according to the Theios (1975) model, less in the difference at the early stages of processing, that is to say sensory coding and identification, than at the intermediate stages involving the decisional process.

\section{Experiment 2: Visual search activity}

Given the cumbersomeness of the procedure, the discomfort of wearing an oculometer for long periods, and the existence of possible artefacts on the subjects' behaviour, we deemed it unacceptable to record the visual search activity throughout experiments; had we done so, our experiment would have lasted several hours. This explains why we have limited, a posteriori, our analysis to complex situations in which the groups differed the most.

\subsection{Method}

\section{Subjects}

Subjects who had participated in the first experiment also took part in the second.

\section{Design and procedure}

Visual search activity was recorded with a video-oculographic apparatus (Nac Eye Mark Recorder V) with an accuracy of $1^{\circ}$ within horizontal and vertical ranges of $\pm 25 / 20^{\circ}$ (Lesbats, 1986). The oculometer was calibrated before and after each sequence. Eye movements were recorded by a $3 / 4$ inch video tape SONY 7630. After the experiment, visual behaviour was analyzed frame by frame using a $3 / 4$ inch SONY videotape (S7630) sending a $30 \mathrm{~Hz}$ signal superimposed on each frame by a SONY frame coder (FCG700). During data collection each event was coded by an operator according to a specific grid of analysis.

\section{Task description}

The perceptual demand of this situation was similar (number of items and durations) to Situation 3 used in the first experiment, but the script differed. During the test, subjects also had to respond with a joystick as previously presented, but only their visual search activity was analyzed and reported.

\section{Dependent variables}

The subjects' visual patterns were divided into specific zones: head, trunk, arm/fist, pelvis, legs, and unidentified fixations. For each group, we analyzed: spatial visual behaviour (nature, number and frequency of visual fixations related to displayed events), temporal visual behaviour (mean duration and total duration of each class of fixations), and visual scan-paths.

\section{Statistical analysis}

A One-way ANOVA, with expertise level as the between-factor, was used to study the effects of level of expertise on cue fixations (total duration of fixations, number of fixations/cue, and mean fixations duration/cue). Non parametric analysis was applied to the cue priorities in each group.

\subsection{Results and discussion}


The total number of fixations was related to the level of expertise $(\mathrm{EXP}=43.3 \pm 17.12$, INT $=$ $105.8 \pm 33.59, \mathrm{NOV}=122.67 \pm 42.41)$. An ANOVA showed an effect of group $(\mathrm{F}(2,15)=9.77 p$ 0.0019). A post-hoc analysis (Scheffe's $F$ test) showed that experts differed significantly from intermediates $(p<0.05)$ and from novices $(p<0.01)$. Difference between intermediates and novices failed to reach the level of significance. This result showed that experts made two and three times fewer fixations than intermediates and novices respectively. It confirms the literature findings reported in the introduction according to which the higher the level of expertise, the smaller the number of fixations.

\section{Specific visual fixations}

Results demonstrated that specific fixations mainly concerned the upper part of the body: head (EXP = $42.6 \%$ vs. INT $=29.9 \%$ vs. $\mathrm{NOV}=19.7 \%$ ), arm-fist $(\mathrm{INT}=22.6 \%$ vs. INT $=34.9 \%$ vs. $\mathrm{NOV}=$ $33.8 \%)$ and trunk $(\mathrm{EXP}=20.3 \%$ vs. INT $=24.9 \%$ vs. $\mathrm{NOV}=17.6 \%)$ while the lower body (pelvis, legs) was not fixated by experts, and only to a small extent by intermediates (3.1\%) and novices (6.68\%) (Fig. 2). This result does not conform to coaches' advice to pay attention to the lower part of the body from which decisive strokes may be triggered. It rather suggests, as demonstrated by Posner et al. (1980), that the locus of attention can be detached from the locus of fixation, and that visual information can occur without eye movement. In our experiment, subjects probably used information from the lower part of the body in peripheral vision without orienting their gaze towards it. Due to the very low number of fixations towards the lower part of the body, we will focus on fixations directed towards the upper part of the body (Fig. 2).

A Kruskal-Wallis test showed that each group had its own priority and that changes in priority were related to level of expertise. The head was fixated mainly by experts $(49.31 \%)$, while intermediates $(37.5 \%)$ and novices $(38.58 \%)$ focused particularly on arm/fist. The difference in priority only concerned fixations on the head $(\mathrm{H}=10.15, p=0.006)$ and on the $\operatorname{arm} /$ fist $(\mathrm{H}=7.94, p=0.019)$ while the trunk revealed no group difference. A complementary analysis (Mann-Whitney $U$ test) specified the differences between groups. It showed that differences concerned only the head (EXP vs. INT, $p=$ 0.01 ; EXP vs. NOV, $p=0.001$ ), and arm/fist between experts and the other two sample groups (EXP vs. INT, $p=0.01$; EXP vs. NOV, $p=0.01$ ).

\section{Intra-group differences}

A Wilcoxon matched pair test of intra-group priorities showed differences between cue preferences, and revealed a transfer of priority between cues, from experts to novices, with intermediates situated between these two contrasted groups. Experts mainly focused on the head $(p<0.026)$, and novices focused on arm/fist $(p<0.046)$, while visual behaviour of intermediates was divided between the different cues in a more homogeneous way.

\section{Total fixation duration}

This concerned the sum of different visual fixations on each cue. Fig. 3 shows that total duration fixation was related to the level of expertise. Difference concerned fixations on the head (EXP $=40.92$ s vs. $\mathrm{INT}=22.39$ vs. $\mathrm{NOV}=9.2)$, on the arm-fist $(\mathrm{EXP}=6.29 \mathrm{~s}$ vs. $\mathrm{INT}=18.01$ vs. $\mathrm{NOV}=29.62)$, and on the trunk $(\mathrm{EXP}=7.7 \mathrm{~s}$ vs. INT $=17.24 \mathrm{~s}$ vs. $\mathrm{NOV}=8.39)$.

ANOVA's, with expertise as a between-group factor, were carried out on fixation duration for each zone of fixation. Level of expertise affected total fixation duration on the head $(\mathrm{F}(2.17)=11.22, p=$ $0.001)$ and on arm/fist $(\mathrm{F}(2.17)=18.31, p=0.0001)$ while no difference appeared for the trunk. Posthoc analysis (Scheffe's $F$ ) showed significant differences $(p<0.05)$ between all groups for arm/fist fixations (EXP vs. INT, $F=4.64$; EXP vs. NOV, $F=18.31$; INT vs. NOV, $F=4.52$ ). For the head, the only significant difference was between experts and novices $(F=11.15)$. An ANOVA, with zone of fixation as the within-factor, carried out for each group on total fixation duration, revealed an effect 
for experts $(\mathrm{F}(2.17)=11.22, p=0.001)$ and novices $(\mathrm{F}(2.17)=11.8, p=0.0023)$ only. A post-hoc analysis showed that experts and intermediates focused on the head and arm-fist respectively.

\section{Mean duration fixation}

Fig. 4 shows that mean fixation duration differed between groups. These differences mainly concerned the head vs. trunk and arm/fist for experts, and arm/fist vs. head and trunk in novices; this difference was smaller in intermediates. It is worth noting that the mean fixation duration on the head was particularly high in experts, reaching nearly $2423 \mathrm{~ms}$. This confirms previous results showing that experts organize their search around a visual point of fixation considered as a visual pivot.

ANOVAs, with expertise as between-factor revealed an effect for the head zone only $(\mathrm{F}(2.17)=$ $20.55, p$ 0.0001). A post-hoc analysis (Scheffe's $F)$ revealed significant differences $(p<0.05)$ for experts vs. inters ( $F$ 11.60], and experts vs. novices ( $F$ 18.44). ANOVAs, with zone of fixation as within-factor were carried out in each group. Results showed a significant effect for experts $(\mathrm{F}(2.17)$ $17.82, p 0.0005)$ and novices $(\mathrm{F}(2.17) 6.34, p 0.016)$ while no difference appeared for intermediates. A post-hoc analysis confirmed previous results on the other parameters and showed that experts and novices focused on the head zone and the arm/fist zone respectively, while intermediates showed more homogeneous visual search activity.

\section{Scan-paths}

Fig. 5 shows the scan-paths for the three groups. These diagrams, concerning connections between cues, provide a dynamic description of visual behaviour and complete the analyses carried out on different cues considered separately.

These diagrams showed differences between groups. For experts, the head, which was in relation to the trunk, on the one hand, and to the arm/fist, on the other, can be considered as a visual pivot around which visual search activity was organized. Indeed, the different cues were closely connected and the scan-path was circular. The scan-path of intermediates, who concentrated most of their eye movements on the arm/fist, was quite similar. In this group, the different cues were still closely related and the scan-path circular. A major difference concerned the novices' scan-path; they were less concentrated on the upper part of the body, and the pelvis came to play a more important role. The novices' strategy could be considered better biomechanically, because it was at the intersection of all possible cues. However, it seems that focusing on the fists prevents focusing on the head, which is well known to be a source of potential information in boxing. Also, it seems preferable to focus on the head, which is relatively motionless, than on the fists, which are always mobile. On the other hand, relations between cues were more linear than circular and the cues were associated in pairs (head-arm/fist, trunk-arm/fist and pelvis-arm/fist), and the arm/fist was the prominent cue. A large number of fixations were not directed at specific zones. This was particularly the case for experts and intermediates for whom the gaze was aimed just over the head. This corresponded to an inter-event or holistic pattern through which boxers analyze several scattered pieces of information from a single point of view. Such visual behaviour is quite similar to the behaviour of expert players described by Ripoll (1988) in a problem solving task in volleyball. The author showed that experts oriented their gaze at the intersection of different cues. Such behaviour is used when information is complex, present in different spatial areas and when time element is stressed.

\section{General discussion}

Results confirmed that expert athletes develop specific cognitive skills to solve complex sports problem situations. Laboratory research must use complex tasks in which an appreciable quantity of information is to be processed during a time unit. This is obtained by combining: (i) a high level of event complexity replicating the natural task demand, (ii) a high level of response complexity, by using multiple types of stimulus response associations, and (iii) a high level of stress, by limiting allowed response time or by using a continuous flow of information. 
It seems important to combine experiments aimed at directly studying mental processing and experiments aimed at studying visual search activity. We have demonstrated that experts used a synthetic mode of visual behaviour, and it seems reasonable to conclude that there exists a relation between the type of visual behaviour and the level of performance reached in solving the problem.

We have already shown that expertise has more to do with ability to detect pertinent cues than with increasing speed of response. Expert boxers tended to be more conservative than non-experts and preferred ignoring a possible opening to rejecting a potential attack. This means that complex problem solving sports situations could be likened, to a signal detection task in which subjects have to extract pertinent cues from "noise" (Swets, 1964). Results from the visual search activity analysis fit well with those reported in the literature (e.g., Abernethy, 1991; Ripoll, 1991; Tenenbaum and Bar-Eli, 1993). A relation exists, whatever the level of expertise, between the temporal and spatial components of visual behaviour. More frequently fixated cues are also fixated for a longer time and with a longer mean duration. Each group favoured specific cues and specific visual patterns. Experts developed more economical visual search activity than less proficient subjects. Fewer fixations occurred (three times less for experts) and they were of longer duration. Experts produced inter-event visual patterns involving a circular relation between selected cues while novices developed a more linear pattern. Such circular and inter-event behaviour resulted in a chunking process by which elements that occur in close temporal proximity, tend to coalesce into a pattern (De Groot, 1966). This type of processing, appreciated as a cognitive skill by Glencross (1989), is for Keele (1986) an essential aspect of skill acquisition. This behaviour is assimilated to a strategy that consists in the manner in which subjects organize their visual search activity by using some constant principles of functioning. This shows a well-adapted attentional organization which is associated with the higher level of expertise in sport.

Such behaviour leads to two possible explanations related to underlying psychological and psychophysiological mechanisms. From a psychological point of view, expert boxers use the covert orientation of attention which is the ability to allocate visual-spatial attention to different locations and to use diffused attention. This specific type of attention was first described by Posner (1980) and then described in expert boxers by Nougier et al. (1989). From a psychophysiological point of view, experts' visual behaviour reveals a complementarity between focal and peripheral vision. Peripheral vision plays the role of alertness in detecting relevant cues and in analyzing their interrelations. Once the pertinent cue is detected, the focal vision analyses it very accurately. This means that, as shown by Vurpillot (1971), peripheral vision works at the global or "inter-figural" level and places in relation the different local elements of the figure, whereas central vision works at the local or "intra-figural" level of the figure and analyses each precise piece of information.

Finally, it seems necessary to qualify the affirmations of Goulet et al. (1989) and Abernethy and Russell (1987) according to whom visual search activity is not a reliable indicator of the subject's level of expertise. Our results in fact confirm that differences in visual behaviour related to the level of expertise, appear mainly when the test-presentation is continuous, last for a relatively long period of time and present a high level of uncertainty with regard to the chronology and the nature of events. The reason why Goulet et al., and Abernethy and Russell found no such differences could be a consequence of their experimental framework. Their conclusions should, therefore, be restricted to the conditions used in their experiment and not be used to contest the pertinency of the analysis of visual search activity per se.

\section{Acknowledgements}

The authors gratefully acknowledge Vincent Nougier (University of Grenoble, France), FrançoisXavier Li, and Mark Scott (Manchester Metropolitan University, UK) for helpful comments on earlier versions of this paper.

\section{References}

Abernethy, B., 1990. Expertise, visual search, and information pick-up in squash. Perception 19, 63-77. 
Abernethy, B., 1991. Visual strategies and decision-making in sport. International Journal of Sport Psychology 22, 189-210.

Abernethy, B. and D.G. Russell, 1987. The relationship between expertise and visual search strategy in a racquet sport. Human Movement Science 6, 283-319.

Allard, F., Graham, S. and M.E. Paarsalu, 1980. Perception in sport: Basketball. Journal of Sport Psychology 2, 14-21.

Allard, F. and J.L. Starkes, 1980. Perception in sport: Volleyball. Journal of Sport Psychology 2, 22-53. Bard, C. and M. Fleury, 1976. Analysis of visual search activity during sport problem situations. Journal of Human Movement Studies 2, 214-222.

De Groot, A.D., 1966. Thought and choice in chess. The Hague: Mouton.

Glencross, D., 1989. 'Cognitive science, human performance and sports psychology'. In: C.K. Giam, K.K. Chook and K.C. Teh (eds.), Proceedings of the 7th World Congress in Sport Psychology (pp. 83-85). Singapore: Singapore Sport Council.

Godinho, M., 1986. Estudo da estratégia perceptiva visual: Influencia das variaveis nivel de pratica e situaàao de jogo [Study of strategy of visual perception: Influence of various level of practice is game sports situation]. Motricidade Humana 1, 57-77.

Goulet, C., C. Bard and M. Fleury, 1989. Expertise differences in preparing to return a service serve: A visual information processing approach. Journal of Sport and Exercise Psychology 11, 382-398.

Hella, F., 1983. Contribution de l'étude du champ visuel à la connaissance de l'espace de travail [Contribution to the study of the visual field to the understanding of the working space]. Le Travail Humain 46, 11-32.

Helsen, W. and J.M. Pauwels, 1990. 'Analysis of visual search activity in solving tactical game problems' In: D. Brogan and K. Carr (eds.), Visual search (pp. 177-184). London: Taylor and Francis.

Keele, S.W., 1986. 'Motor control'. In: K.R. Boff, L. Kaufman and J.P. Thomas (eds.), Handbook of perception and human performance. Vol 2: Cognitive processes and performance (pp. 1-60). NewYork: Wiley.

Kerlirzin, Y., 1990. Traitement des informations visuelles et prises de décision en boxe française [Visual information processing and decision making in French boxing]. Unpublished master's thesis. Institut National du Sport et de l'Education Physique, Paris.

Lerda, R., 1993. Les déterminants cognitifs des conduites de décision: le cas du football [Underlying cognitive processes in decision in soccer]. Unpublished doctoral dissertation, Université Aix-Marseille 2 .

Lesbats, M., 1986. Le suiveur d'activité oculaire NAC modèle V [The analyser of ocular activity]. Le Travail Humain 49, 163-170.

Levy-Schoen, A., 1972. 'Rapport entre mouvement des yeux et perception' [Relationship between eye movements and perception]. In: H. Hecaen (ed.), Neuropsychologie de la perception visuelle (pp. 7692). Paris: Masson.

Mackworth, N.H. and J.S. Bruner, 1970. How adults and children search and recognize pictures? Human Development 13, 149-177. 
Malho, F., 1969. L'acte tactique en jeu [The tactical act in games]. Paris: Vigot.

Nougier, V., H. Ripoll and J.F. Stein, 1989. Orienting of attention with highly skilled athletes. International Journal of Sport Psychology 20, 305-223.

Papin, J.P., P.J. Metges and P.R. Amalberti, 1984. 'Use of Nac Eye Mark Recorder by radiologists'. In: A.G. Gale and F. Johnson (eds.), Theoretical and applied aspects of eye movement research (pp. 323330). Amsterdam: North-Holland.

Papin, J.P., 1987. 'L'éducation des stratégies de prise d'informations visuelles' [The teaching of visual information processing strategies]. In: R.H. Ripoll and G. Azemar (eds.), Neurosciences du sport: Traitement de l'information visuelles, prise de décision et réalisation de l'action en sport (pp. 389-411). Paris: INSEP.

Petrakis, E., 1986. Visual observation patterns of tennis teachers. Research Quarterly for Exercise and Sport 57, 254-259.

Petrakis, E., 1987. Analysis of visual search patterns of dance teachers. Journal of Teaching in Physical Education 6, 149-156.

Posner, M.I., 1980. Orienting of attention. Quarterly Journal of Experimental Psychology 32, 3-25. Posner, M., E. Snyder and B. Davidson, 1980. Attention and the detection of signals. Journal of Experimental Psychology: General 109, 160-174.

Ripoll, H., 1979. Le traitement de l'information de données visuelles dans les situations tactiques en sport: L'exemple du basket-ball [The processing of visual information in tactical sport situations: basketball]. Travaux et recherches en EPS 4, 99-104.

Ripoll, H., 1988. Analysis of visual scanning patterns of volleyball players in a problem solving task. International Journal of Sport Psychology 19, 9-25.

Ripoll, H., 1991. The understanding-acting process in sport: The relationship between the semantic and the sensorimotor visual function. International Journal of Sport Psychology 22, 221-250.

Ritzdorf, W., 1983. Antizipation im Sportspiel - dargestellt am Beispiel des Tennisgrundschlags. Leistungssport 13, 5-9.

Salmela, J.H. and P. Fiorito, 1979. Visual eues in ice-hockey goaltending. Canadian Journal of Applied Sport Sciences 4, 56-59.

Swets, J., 1964. Signal detection and recognition by human observers: Contemporary readings. NewYork: Wiley.

Tenenbaum, G. and M. Bar-Eli, 1993. 'Decision-making in sport: A cognitive perspective'. In: R.N. Singer, M. Murphey and L.K. Tennant (eds.), Handbook of research in sport psychology (pp. 171-192). New York: Macmillan.

Theios, J., 1975. 'The components of response latency in simple human information processing task'. In: P. Rabbitt and S. Dornic (eds.), Attention and performance V (pp. 418-440). London: Academic Press.

Vurpillot, E., 1971. Introduction à l'étude du rôle des déterminants perceptifs de l'organisation spatiale [Introduction to the study of the perceptifs factors involved in spatial organization]. Cahiers de Psychologie 14, 317-323.

Westphal, C., 1982. 'Zur Messung der Wahrnehmungs- und Entscheidungsfähigkeit im Volleyballspiel'. 
In: R. Andersen and C. Hagedorn (eds.), Lernen im Sportspiel (pp. 109-116). Berlin: Bartlet et Wernitz. 
Table 1

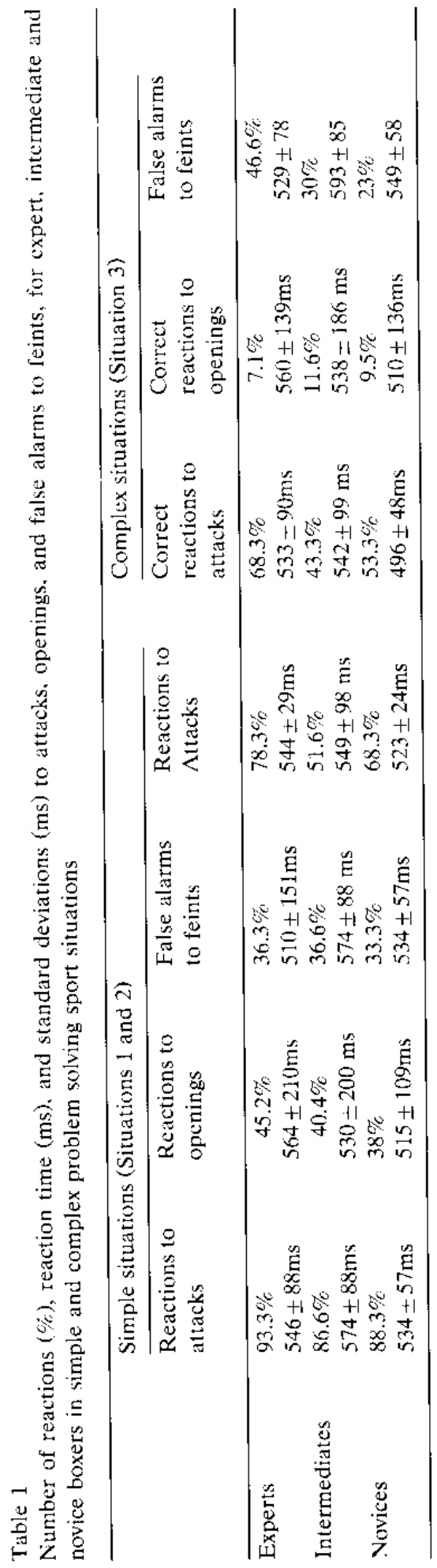


Fig. 1. Percentage of responses to attacks and openings in simple (Situations 1 and 2) and in complex situations (Situation 3) related to the level of expertise.

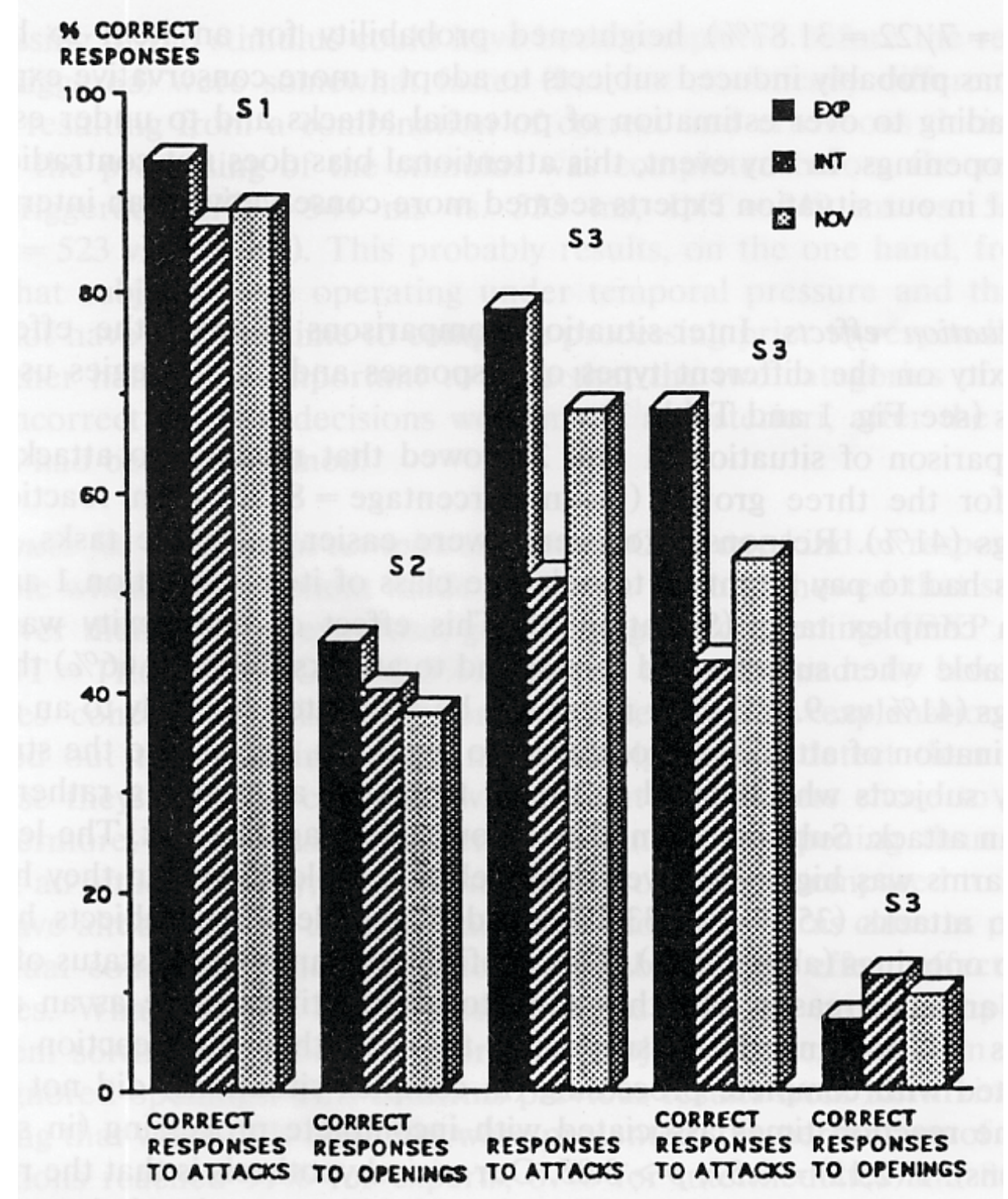


Fig. 2. Frequencies of different types of fixation (ms) on the upper part of the body (head, arm/fist, and trunk) for the different groups.

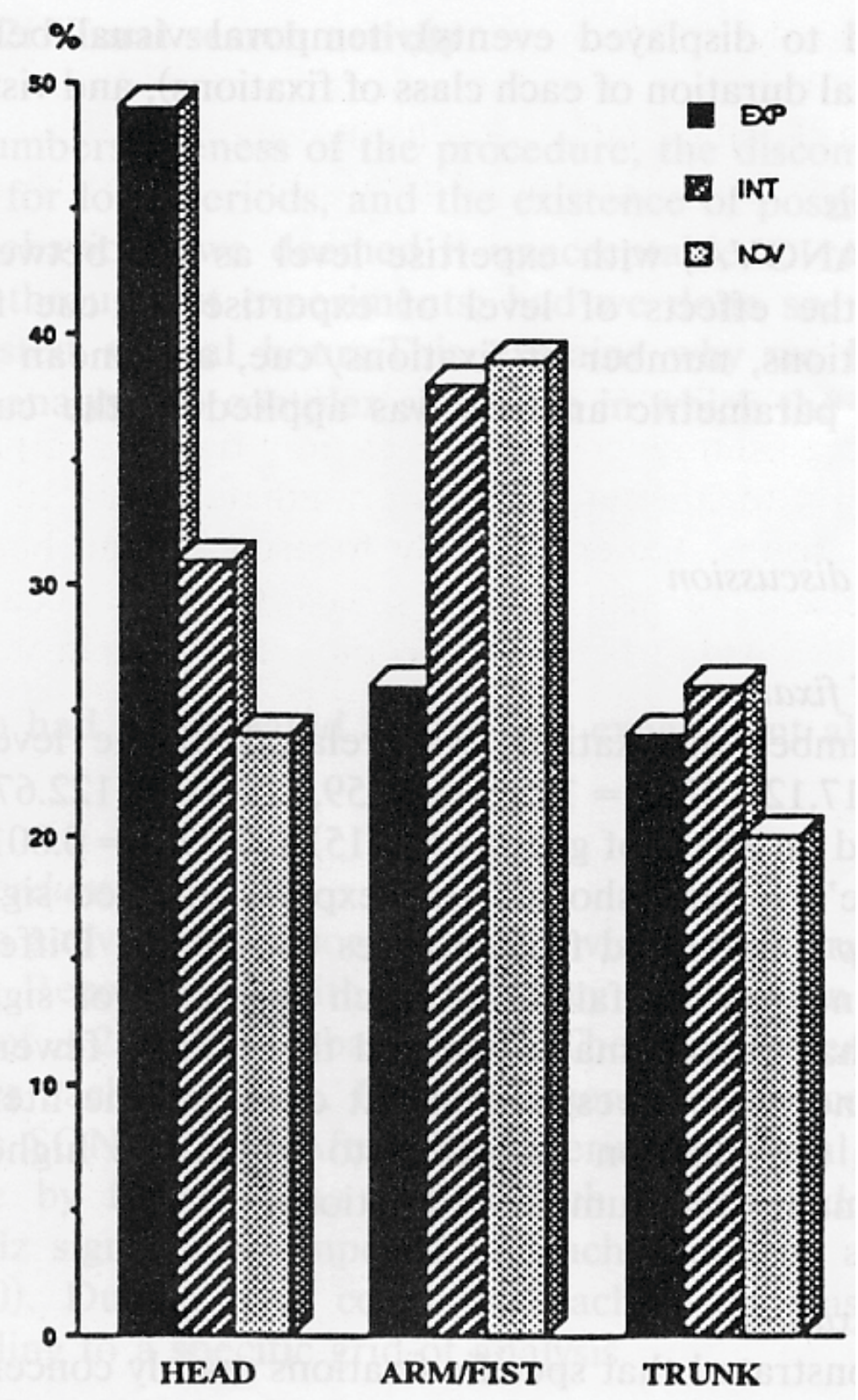


Fig. 3. Total duration of fixation (s) on the upper part of the body for the different groups.

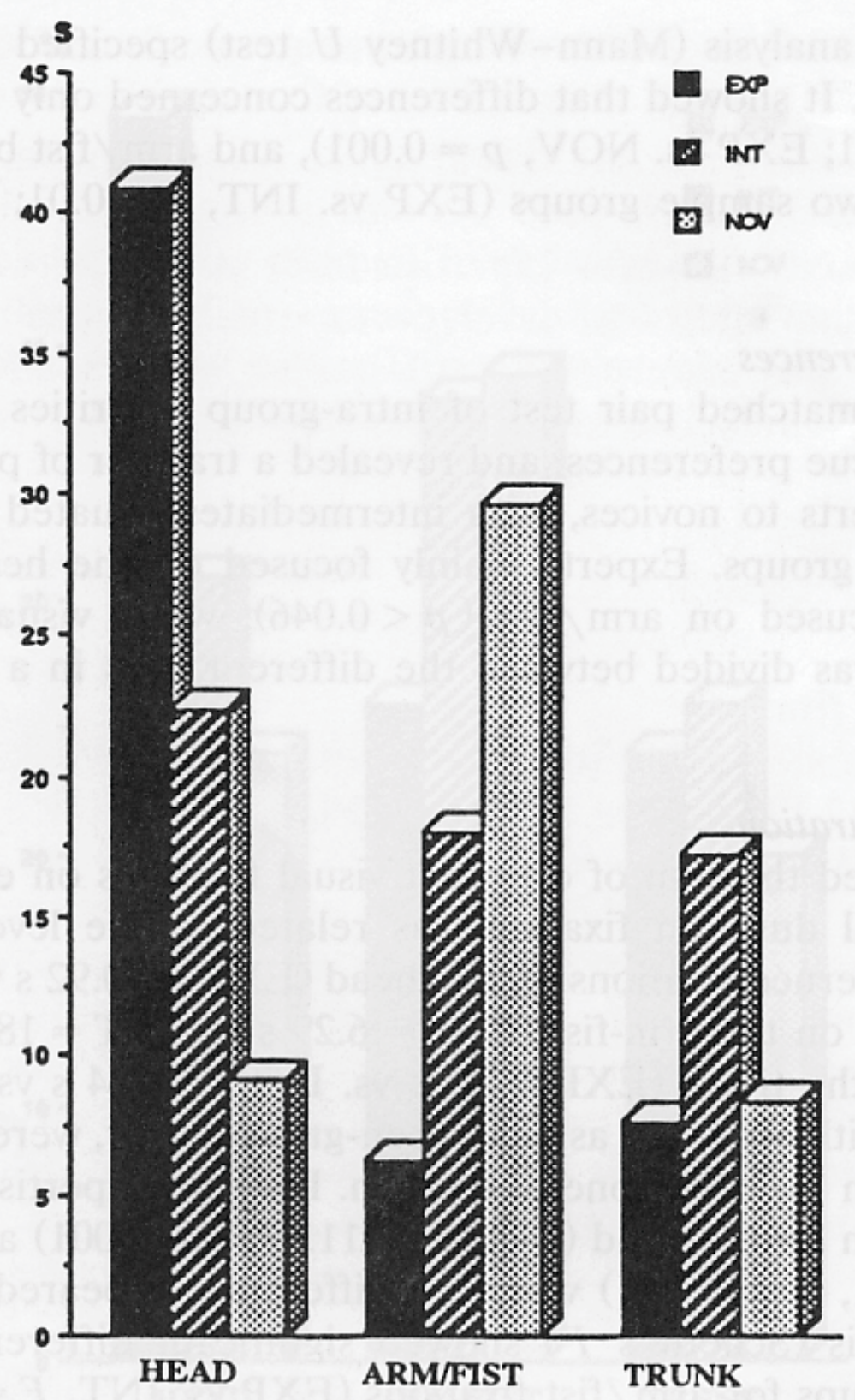


Fig. 4. Mean fixation duration (ms) on the upper part of the body for the different groups.

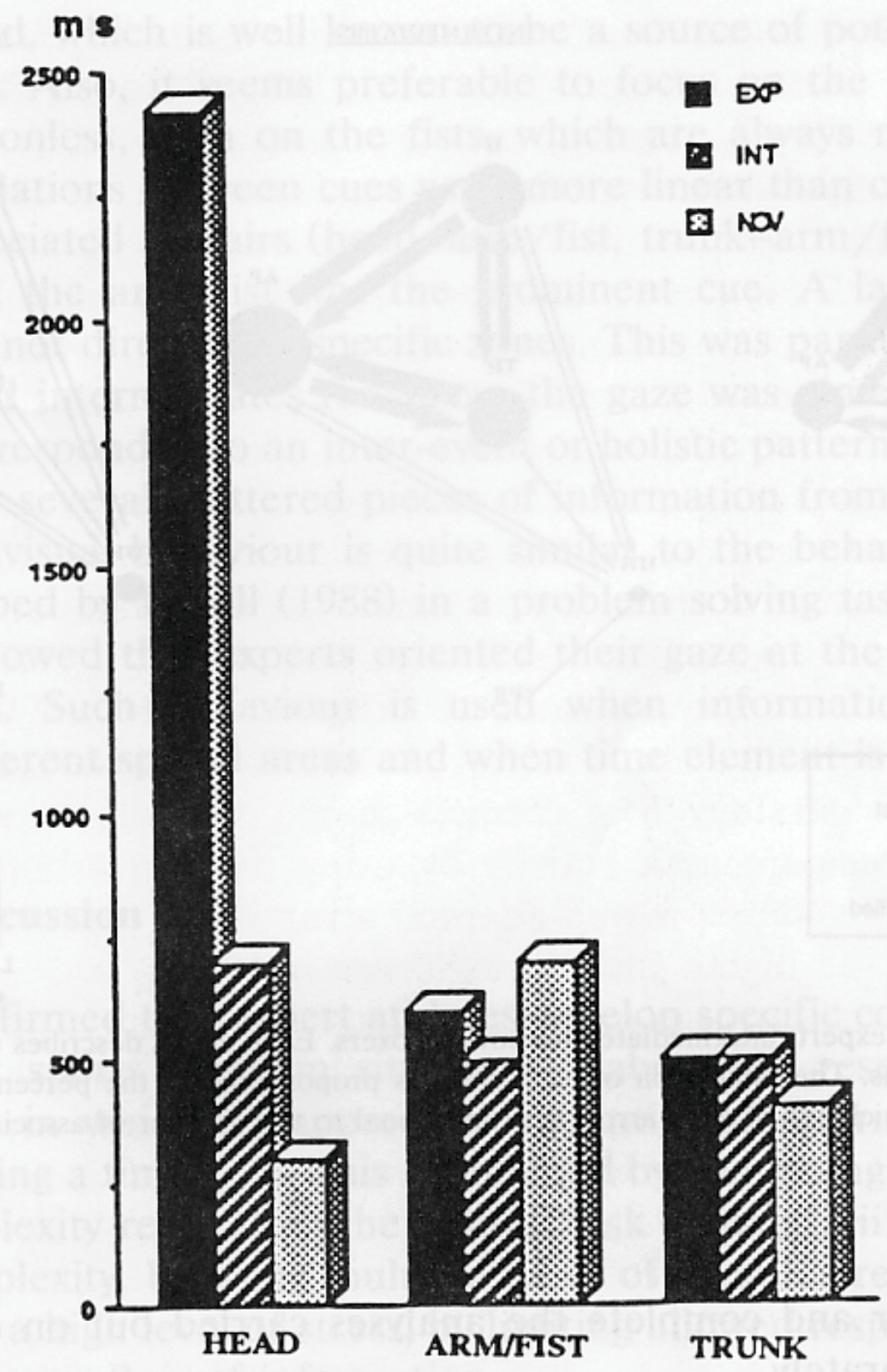


Fig. 5. Scan-paths of expert, intermediate and novice boxers. Each arrow describes the gaze movement between two locations. The dimension of each circle is proportional to the percentage of fixation on each location. The thickness of each arrow is proportional to the number of associations between two locations.

lixPLIR'S

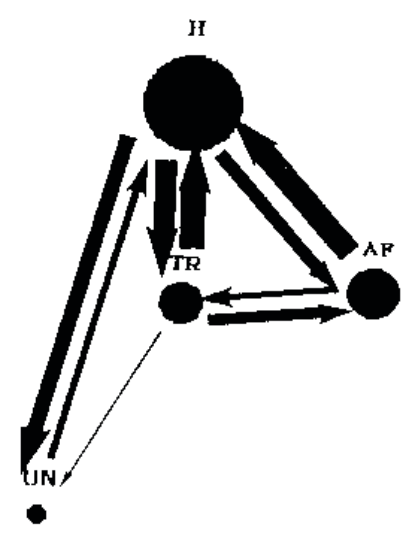

INTILIIMLIBIATLS

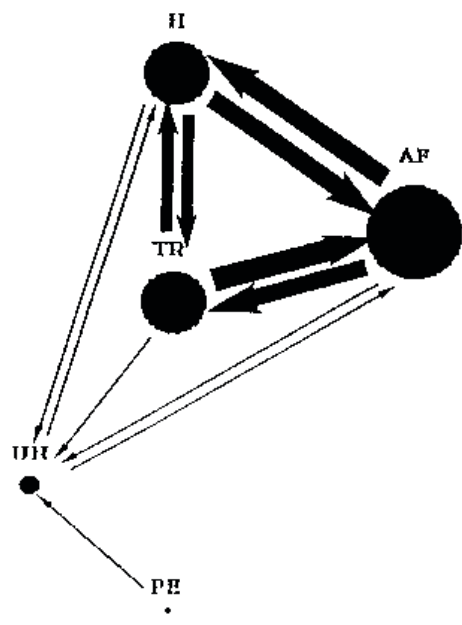

NovICIS

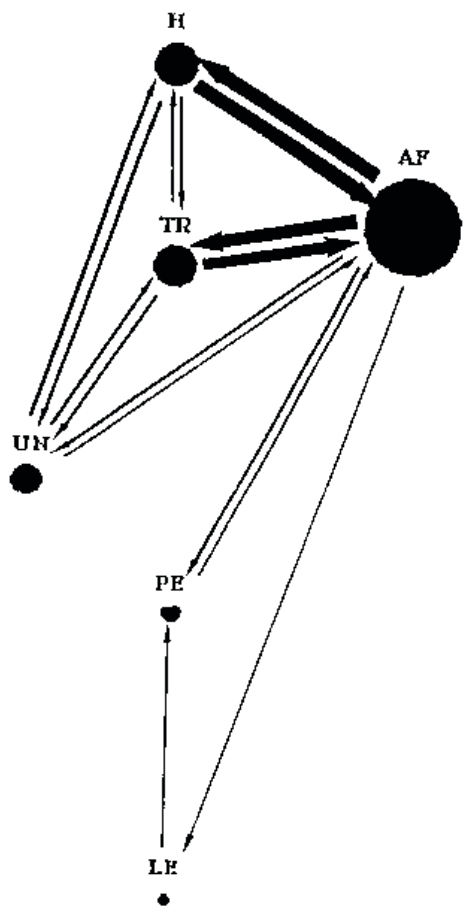

